\title{
A Statistical Trend of the Development of Android Islamic Apps in Malaysia from 2000 To 2017
}

\author{
Muhammad IzzatZakwan Mohd Zabidi ${ }^{1}$, Syamimi Zakaria ${ }^{1}$, Amar Faiz Zainal Abidin ${ }^{1}$, Nur AimanHanis Hasim ${ }^{1}$, \\ Arman Hadi Azahar ${ }^{1}$, Mohamad Haniff Harun ${ }^{1}$ \\ ${ }^{1}$ Faculty of Electrical and Electronic Engineering Technology, UniversitiTeknikal Malaysia Melaka, Malaysia. \\ izzat.zakwan@utem.edu.my, amarfaiz@utem.edu.my,nuraiman@utem.edu.my, arman.hadi@utem.edu.my, haniff@utem.edu.my.
}

\begin{abstract}
This paper presents the statistical trend related to the Androidbased Islamic apps published in Malaysia's Google App Store from the year 2000 to 2017 . The statistical analysis based on seven point-of-view: 1) category; 2) year; 3) country; 4) price; 5) total download; 6) keyword. This statistical trend analysis aims to give insight for the Android App Developer on the current trend of the Islamic apps published in Malaysia Google App Store.
\end{abstract}

Key words: Islamic app, Android app, statistical trend, consumer app, Malaysia trend.

\section{INTRODUCTION}

Smart phone app development has been increasing rapidly, outpacing the computer-based software development. Nowadays, there are a lot of previous research regarding mobile application.Said et al. discusses the development of a mobile application (app) for creating and managing a grocery list collaboratively named CROLIST [1]. Besides that, a mobile learning for BahasaMelayu based on mobile augmented reality (AR) application had developed by Mohd et al [2]. Next, Sayal et al. make a survey of the latest developments in mobile technologies and mobile appswhich are targeted at bringing back the zest and joy in the lifeof visually impaired people [3].Adistyasari et al. had made research tofind out what factors influence the intention to use P2Plending applications, including knowing the positive impactof perceived ease of use, perceived usefulness, trust, userinnovation, and government support for attitude towardsusing the P2P lending applications, and the positive impact ofattitude towards use for behavioral intention to use P2Plending applications [4].In addition,anIedutech Mobile Application to facilitate theTeaching and Learning (T\&L) process in the classroom forInformation Technology in Educational subjects related toNetwork and Communication topicshad been developed by Ahmad et al [5].

Thus leads to an interesting question: What is the trend in the app development related to Islamic application? This paper attempts to tackle this research question by performing statistical analysis of the trend in the Android Islamic app development from a time frame of 2000 to 2017. The statistical analysis was performed by capturing all the Android apps related to Islamic from Malaysia Google Play Store, starting from 2000 until 2017. As the number of apps published is vast, the Android apps considered for this study are the Android apps that have total downloads higher than 50 downloads on 2 nd July 2018. Thus, any app with a total download less than the specified amount was ignored. Based on these filtering criteria, this study able to capture around 500 apps from three main categories: 1) Islamic practice; 2) Islamic education; 3) others. While each of these main categories has four or five subcategories. There is some information gathered for each app, such as the year published, rating, total download, features, price, keyword, and country of origin.

\section{ISLAMIC APPS BY CATEGORY}

Based on the compilation of around 500 apps, this study identified three main categories that all these apps can be group into (as illustrated in Figure 1). Note that most of the apps have more than one feature, which makes it cover several categories; thus, the method used to determine the main categories of an app is based on the main feature of the app. For example, the Al-Quran Melayu App consists of not only the collection of Quran words with the Malay translation but also the Islamic calendar, and prayer time. As the main feature focuses more on the dua (as the app name suggested), it is categorized under Islamic education with the subcategory of Al-Quran. The three main categories are: 1) Islamic practice; 2) Islamic education; 3) Others. In the Islamic practice categories, there are five subcategories: 1) Qiblat that has 15 apps; 2) Hajj that has 30 apps; 3) Waqaf that has 32 apps; 4) Solat that has 48 apps; 5) Ramadhan that has 54 apps. The interesting point to take note that seems the Ramadhan apps are the most in this category. Under Islamic education, there are three subcategories, which are hadith, Al-Quran, and Arabic. There are four subcategories in the Other category: 1) Matchmaking; 2) Eateries; 3) Ecommerce; 4) Travel. At first, the number of apps published under this category might surprise the reader as this is not the typical themes associated with Islam. Still, if the reader attempts to look from the commercial point of view, the significant number under this category makes sense as these apps can actively engage the users in the commercial transaction. 


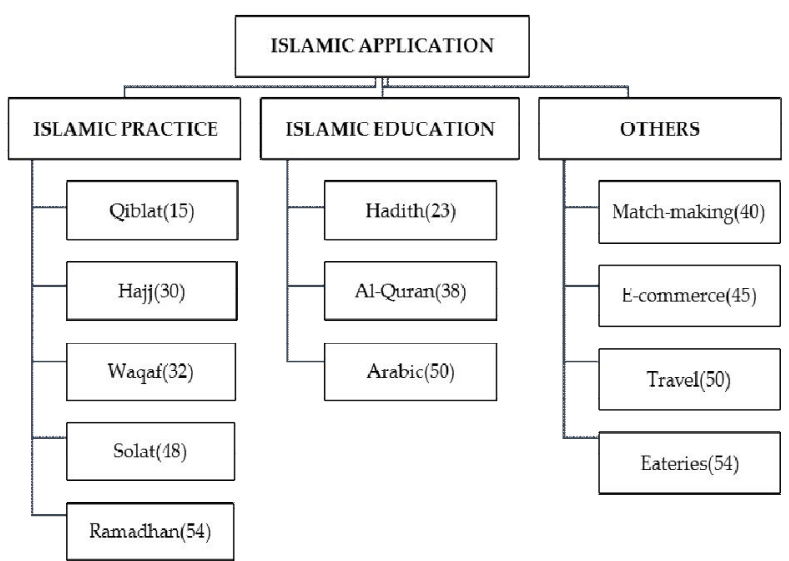

Figure 1: Main categories and subcategories of Islamic Android Apps.

\section{ISLAMIC APPS BY YEAR}

Figure 2 shows the collected data of the publication year of the Android apps. Starting from 2000 until 2004, the total apps published in a year shows a slow trend started by one or two apps. The trend shows a slight increase from 2004 to 2012, where around 10 to 20 apps were published. The year 2012 to 2017 shows a bullish trend in 2012, the number of apps published is just shy of 20 apps, and in 2017 the number of apps published is more than 100 apps per year. This exponential increase is linear to the exponential growth of global smartphone penetration. This phenomenon also shows a significant shift in the changing trend of users who in the late 2000 s use personal computer or laptop as the primary device to access information to the heavy use of smartphone for the same purpose in the late 2010s.

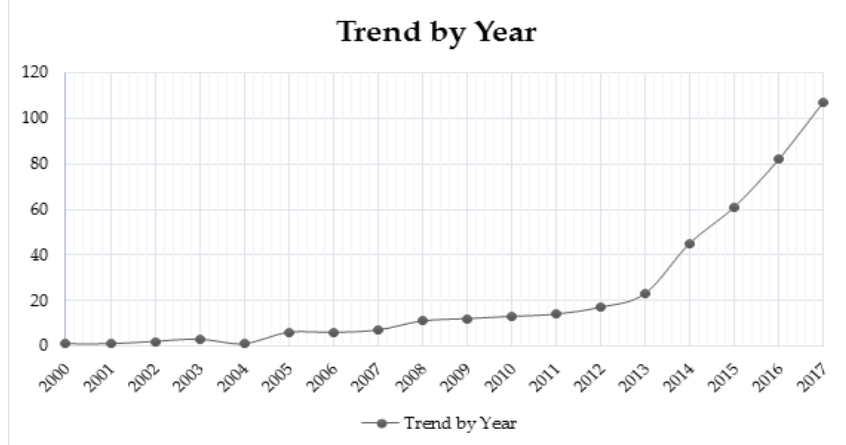

Figure 2:Number of applications published by year.

Figure 3 shows the total apps published per year, according to the sub-categorized classified earlier. Travel app started to introduce their business on google play store in the year 2002, follow by E-commerce in 2002, Hajj in 2003, Salat in 2004, Eateries in 2005, Match-marking 2006, Quran in 2010, Ramadhan in 2011, Qiblat and Wakaf in 2013 then Hadith and Arab in 2014. It also shows that the number of applications increases significantly from 2012 to 2017. The highest application created was Quran in 2017 with $15.7 \%$, and the lowest application made was Qiblat, with $1.6 \%$ of the total highest application designed from 2002 to 2017.

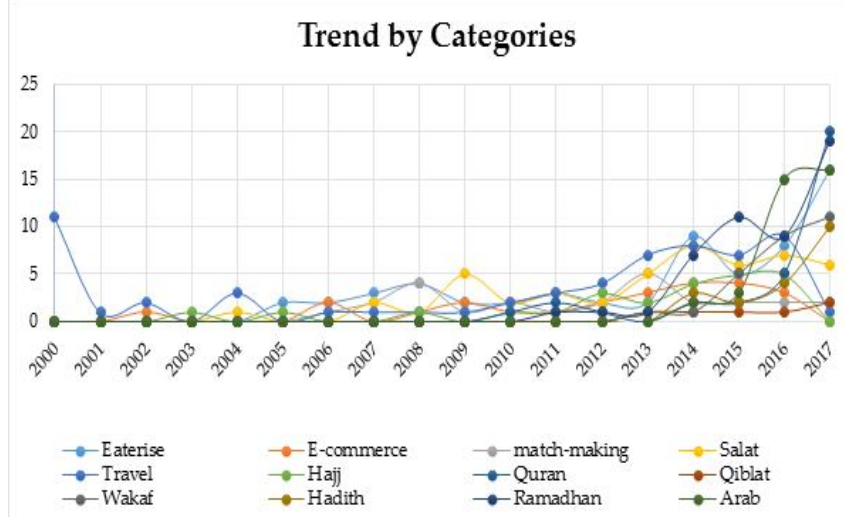

Figure3:Data for each of 12 subcategories application.

\section{ISLAMIC APPS BY FEATURES}

As stated in the earlier section that an app can have more than one feature. This relationship had been illustrated in Figure 4 where a Venn Diagram of all 12 subcategories of the apps are presented in 12 circles (each category represented by a circle). Notice that there are several categories or circle overlap with other categories. The number in red colour shows the number of apps that the overlap features. For example, Eateries application contain not only the location of the Halal restaurant but also the various functions like E-commerce (one app), Travel (20 apps), Solat (one app) and Hadith (five apps). Notice that the Solat app has the most additional features which cover Eateries (20 apps), Hadith (35 apps), Qiblat(6 apps) and Ramadhan (3 apps).

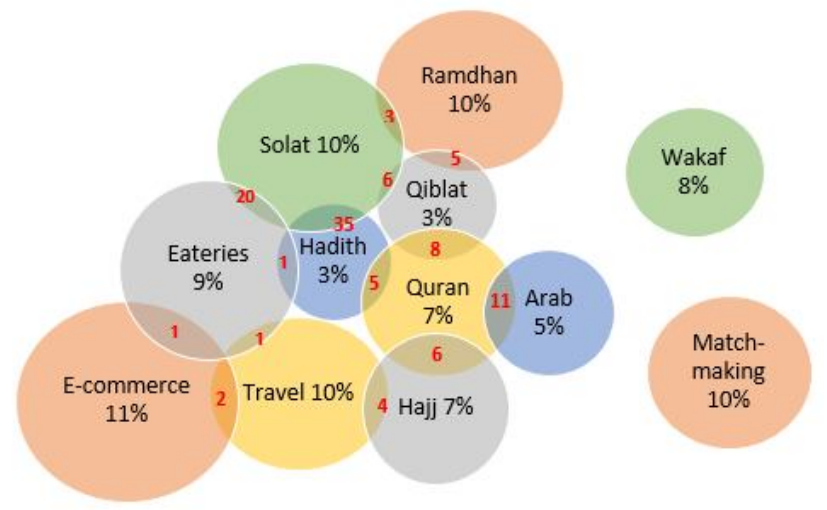

Figure 4:Venn Diagram for Islamic apps.

\section{ISLAMIC APPS BY COUNTRIES}

There is a fascinating fact one might expect most of the apps published in Islamic countries but based on the finding, Islamic countries barely captured $56 \%$ of the total Android apps. Figure 5 shows the pie chart of the countries that dominate the Islamic app development. The pie chart displays nine countries in that place. The highest percent in the chart is Indonesia, with $22 \%$ of the apps developed by that country. Second highest is Arab with 15\%, and the lowest percentage that develops application is Singapore and Japan with $4 \%$ respectively. 


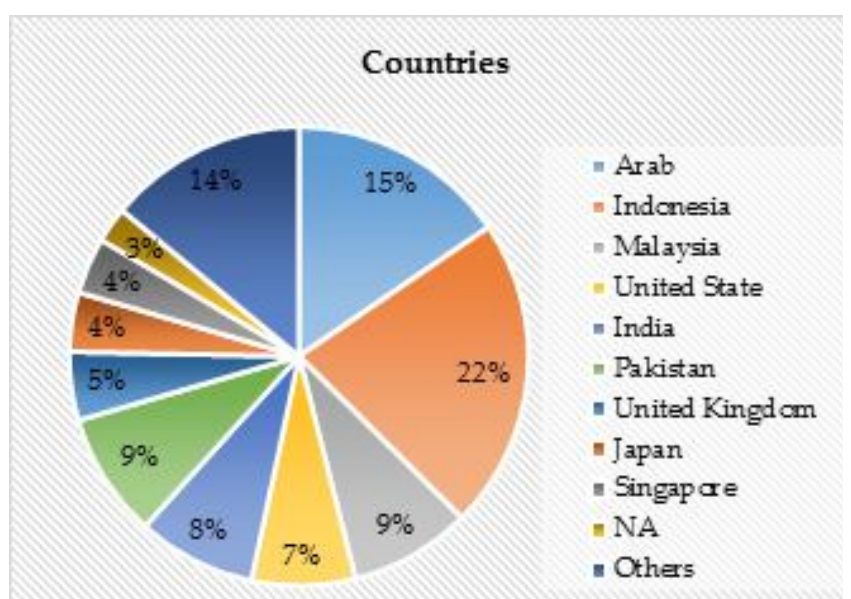

Figure 5: Pie chart for analysis data of the country that created apps in percentage.

\section{ISLAMIC APPS BY TOTAL DOWNLOAD}

Figure 6 shows the total download for all category of Islamic application from one until 100 million downloads. Most of the apps total download is among 1000 to 10,000 , which is $21 \%$. Second highest category is the total downloads from 100,000 to $1,000,000$, and 10,000 to 100,000 by $20 \%$.
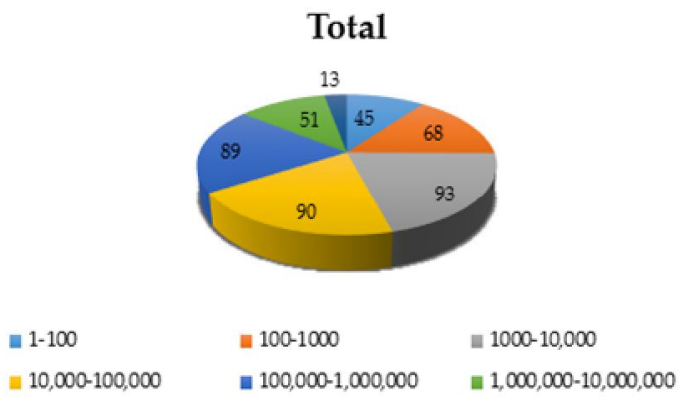

Figure 6: Pie chart of total download.

If the pie chart illustrated in Figure 6 being break into the subcategories, this can be view in Figure 7.

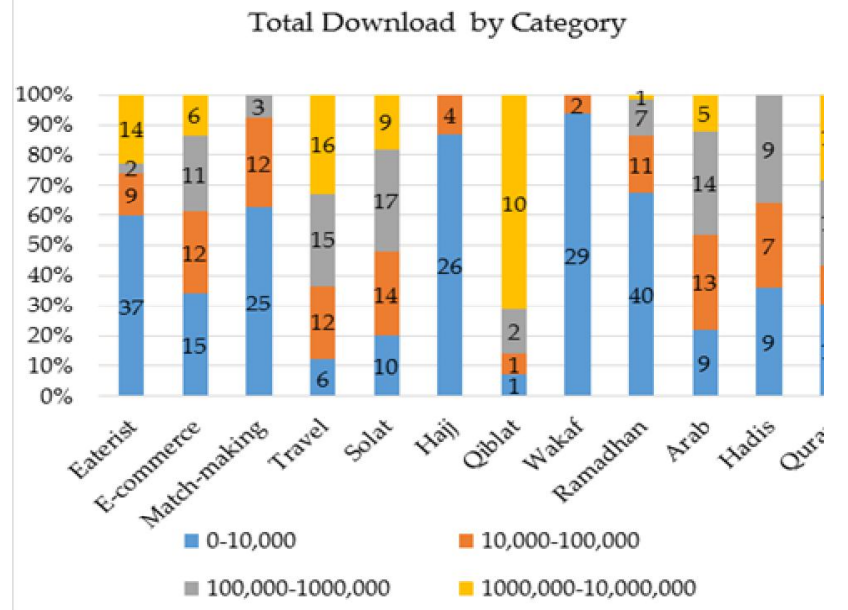

Figure 7:Total download based on the 12 types of categories.
The graph shows about 60\% from Eateries apps had download in the range of 0 to 10,000 and only $3 \%$ apps was download in the range of 100,000 to $1,000,000$. The highest download for E-commerce application is about 0 to 10,000 , with around 35\% apps, and the lowest total download for Ecommerce is 1 million to 10 million that only $14 \%$ of apps were downloaded. Besides that, the graph shows that for Match-making application, $63 \%$ of users download the apps at 0 to 10,000 , which is the highest download. While only $8 \%$ downloaded by users at the range of 100,000 to $1,000,000$. Next, the apps that had downloaded about 0 to 10,000 in Travel application types become the lowest download which is only $12 \%$ apps was download while the highest download is $13 \%$ the total number of downloads at the range of $1,000,000$ to $10,000,000$. Solat application has the lowest download, which is $18 \%$ at the range $1,000,000$ to $10,000,000$ and highest at the range from 100,000 to 1,000,000. In Hajj application, not much people download for it, and only $87 \%$ app has the highest download from 0 to 10,000 , and the rest was download at range 10,000 to 100,000 . Furthermore, $71 \%$ application was download for Qiblat at the range of 1,000,000 to 10,000,000, which is the highest and 7\% for range 0 to 10,000 and 10,000 to 100,000 , respectively. Nevertheless, there was fewer download for Wakaf application, where only $94 \%$ download for range 0 to 10,000 . For Ramadhan application, the highest download is $68 \%$ at range 0 to 10,000 , and the lowest download is $2 \%$ for range $1,000,000$ to $100,000,000$. Besides, $34 \%$ number of download for Arabic language app is in range 100,000 to 1000,000 and the lowest is $12 \%$ at $1,000,000$ to $10,000,000$. The highest number of downloads for Hadis application has the same values between range 0 to 10,000 and 100,000 to $1,000,000$, which are $36 \%$ each respectively while the lowest is $28 \%$ at range 10,000 to 100,000 . Lastly, most Muslim depends on Quran for their life rutin. Therefore, the highest download of Quran app is 30\% for range 0 to 10,000 , and lowest at 10,0000 to 100,000 with $13 \%$ of download. From the analysis, it shows that travel has the highest total 16 app download, which more than one million users.

\section{ISLAMIC APPS BY PRICE}

Figure 8 shows that 99\% from all Islamic Android apps in the Malaysia Google Play Store is free to download where the developer mostly included Google advertisement inside the app to generate revenue from the app. About 12 apps that have in-app purchase from US $\$ 0$ to US $\$ 5$. There are 24 apps priced from to US $\$ 5$ to US $\$ 20$. Surprisingly, only three apps that set a price at the range of US $\$ 100$ to US $\$ 500$.

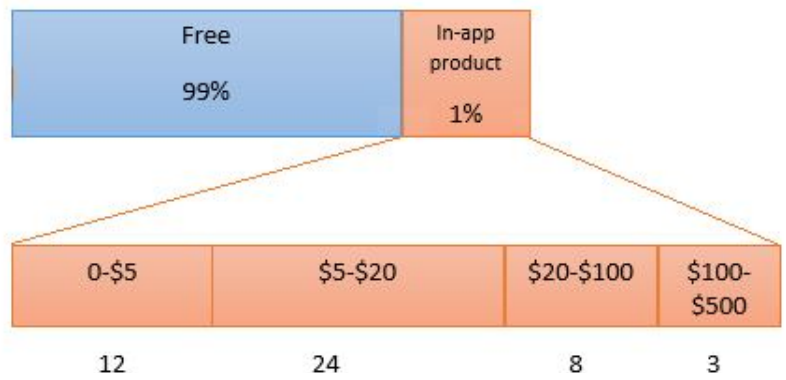

Figure 8: The price range for the Islamic apps. 


\section{ISLAMIC APPS B Y KEYWORDS}

Figure 9 shows the keyword features from all the Islamic apps indexed in this study. The online website, worditout.com is used to calculate and generate a graphical representation of the frequency of the keywords. The bigger the keyword shows a greater frequency of the keyword used to classify the app. Thus, the most dominant keywords are Prayer, Halal, Location, Hadith and Arabic.

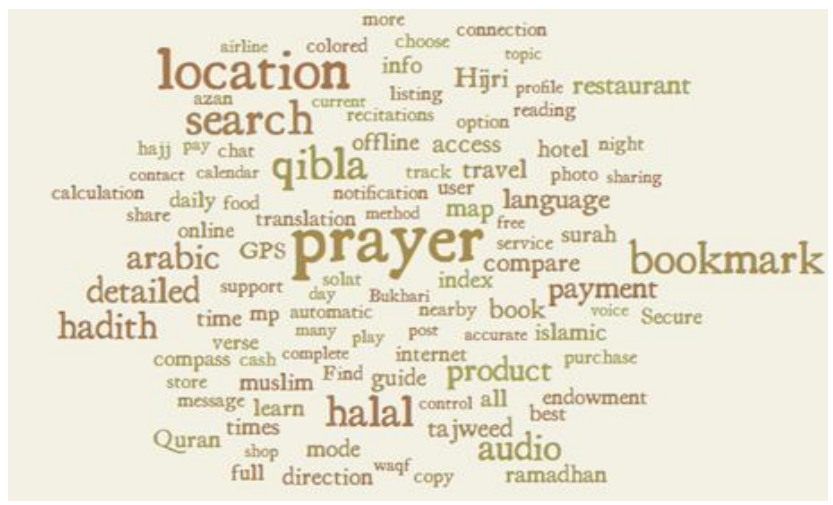

Figure 9: Keywords of the Islamic apps.

\section{CONSLUSION}

This paper presented the statistical analysis related to the Android-based Islamic apps published in Malaysia's Google App Store from the year 2000 to 2017. The statistical analysis covered the following themes: 1) Islamic apps by keywords; 2) Islamic apps by price; 3) Islamic apps by total download; 4) Islamic apps by countries; 5) Islamic apps by features; 6) Islamic apps by year; 7) Islamic Apps by category. Several exciting points found during this study. This study hope can provide insight for the Android App Developer on the current trend of the Islamic apps published in Malaysia Google App Store.

\section{ACKNOWLEDGEMENT}

This paper was supported by Faculty of Electrical \& Electronics Engineering Technology, UniversitiTeknikal Malaysia Melaka (UTeM) under Centre of Research and Innovation Management (CRIM) Publication Incentives.

\section{REFERENCES}

[1] N. S. A. M. Said and N. Katuk. CROLIST: A Mobile App for Collaborative Grocery List Management, International Journal of Advanced Trends in Computer Science and Engineering, Vol 8, No 5, 2216-2223, October 2019.

[2] C. K. N. C. K. Mohd, M. Sidek, N. A. Hadi and N. F. N. M. Daud. Augmented Reality (AR) on Mobile Application for Learning Bahasa Melayu among Primary Students, International Journal of Advanced Trends in Computer Science and Engineering, Vol 8, No 6, 3665-3669, November-December 2019.

[3] R. Sayal, C. Subbalakhmi and H. S. Saini. Mobile App Accessibility for Visually Impaired, International
Journal of Advanced Trends in Computer Science and Engineering, Vol 9, No 1, 182-185, January-February 2020.

[4] N. Adistyasari, R. K. Firmansyah and W. Gunadi. Analyzing the Use of P2P Lending Mobile Applications in Greater Jakarta, International Journal of Advanced Trends in Computer Science and Engineering, Vol 9, No 2, 2010-2020, Mac-April 2020.

[5] F. Ahmad, N. Hamzah, W. A. S. W. Hassan and A. H. Mansor. "Iedutech" Mobile Application Development for InformationTechnology Subjects in Education among TVET Students, International Journal of Advanced Trends in Computer Science and Engineering, Vol 9, No 3, 2955-2960, May-June 2020. 